\title{
PERENCANAAN KEBIJAKAN PENGELOLAAN SUKU CADANG CORAZZA A452 DAN CORAZZA FF100 LINE 3 MENGGUNAKAN METODE RELIABILITY CENTERED SPARES (STUDI KASUS : PT XYZ)
}

\author{
${ }^{1}$ Triastuty Pardede, ${ }^{2}$ Rd. Rohmat Saedudin, ${ }^{3}$ Sutrisno \\ 1,2,3Program Studi Teknik Industri, Fakultas Rekayasa Industri, Telkom University \\ 1'triastutypardede@gmail.com, ${ }^{2}$ rdrohmat@telkomuniversity.ac.id, ${ }^{3}$ sutrisno_mr@yahoo.com
}

\begin{abstract}
Abstrak - PT XYZ menghasilkan produk keju olahan yang memiliki 6 line varian produk. Salah satu produknya ada pada sistem line 3. Berdasarkan downtime karena ketidatersediaan suku cadang mesin setiap line, line 3 memiliki total downtime mesin tertinggi. Selain itu, kinerja mesin sangat mempengaruhi hasil produksi. Proses produksi pada line 3 ini dimulai dari cooking pada sthepan kettle, filling pada corazza FF100 dan packing cartoon mesin corazza A452. Mesin Corazza FF100 dan corazza A452 memiliki jumlah frekuensi kerusakan tertinggi pada line 3. Hal tersebut akan sangat mempengaruhi proses produksi. Untuk mendukung kinerja mesin maka dibutuhkan suku cadang yang selalu tersedia ketika ada komponen atau part yang mengalami kegagalan atau kerusakan. Penentuan criticality items membantu prioritas pengadaan suku cadang menggunakan Reliability Centered Spares (RCS). Selain itu, penentuan jumlah kebutuhan suku cadang selama satu periode juga diperlukan untuk memastikan berapa banyak suku cadang yang dibutuhkan selama satu periode menggunakan metode Poisson Process. Penentuan minimum dan maksimum stock level berdasarkan service level juga akan membantu untuk memastikan suku cadang akan selalu tersedia saat dibutuhkan dan mengurangi kemungkinan stockout. Pada hasil RCS didapatkan 5 komponen dan 8 parts kritis pada Corazza A452, 1 komponen dan 18 parts pada Corazza FF100 yang termasuk pada level criticality A dan B. Selanjutnya dengan metode Poisson Process didapat jumlah kebutuhan suku cadang periode 1 tahun dan stock level berdasarkan service level didapatkan jumlahnya untuk masingmasing komponen dan parts.
\end{abstract}

Keywords: Reliability Centered Spares, Poisson Process, Service Level

\section{PENDAHULUAN}

Kebutuhan masyarakat terhadap makanan olahan keju menjadi target yang ingin dipenuhi PT XYZ. PT XYZ mendukung kegiatan produksi untuk mencapai targetnya dengan cara tetap menjaga kinerja mesin yang digunakan ketika melakukan proses produksi. Hal ini dikarenakan ketika kinerja mesin menurun maka produksi akan sulit untuk mencapai target yang diinginkan. PT XYZ melakukan perhitungan kinerja mesin yang dapat dilihat pada Gambar 1 . Berdasarkan pada Gambar 1 dapat diketahui bahwa loading time mesin mampu menghasilkan 55 pack per jam pada line 3. Loading time mesin merupakan waktu mesin dapat beroperasi. Kinerja mesin $40 \%$ pada grafik tersebut memberikan informasi bahwa mesin hanya dapat menghasilkan kurang lebih 22 pack per jam.

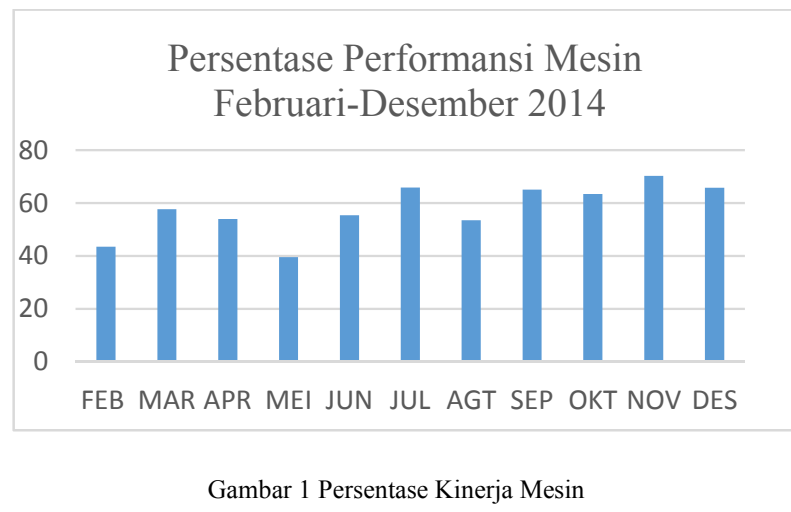

Kinerja mesin yang mengalami penurunan dapat dilihat saat mesin tidak beroperasi atau ketika downtime terjadi yang disebabkan oleh ketidaktersediaan suku cadang, kegiatan maintenance [1] yang kurang efektif, kekurangan SDM ahli untuk memperbaiki mesin. Dampak downtime mesin dapat menyebabkan kegiatan produksi sulit mencapai target yang diinginkan. Adapun total downtime dari masing-masing line produksi PT XYZ selama periode tahun 2013 sampai tahun 2014 dapat dilihat pada Tabel I. Pada Tabel I, total downtime tertinggi berada pada line 3 . Penyebab total downtime tinggi di 
line 3 dikarenakan ketidaktersediaan suku cadang yaitu 27804 menit dari total downtime 32804 menit $(85 \%$ dari total downtime). Adapun mesin-mesin yang digunakan untuk produksi di line 3 dalam proses pembuatan produknya antara lain Stephan Kettle, Corazza FF100 dan Corazza A452. Alur proses produksi line 3 dapar dilihat pada Gambar 2. Mesin Stephan Kettle digunakan untuk melakukan cooking sesuai dengan formula yang telah disiapkan, Mesin Corazza FF100 digunakan untuk proses filling keju dan Mesin Corazza A452 digunakan untuk proses cartooning.

TABEL I

TOTAL DOWNTIME

\begin{tabular}{|c|c|c|c|c|}
\hline \multirow{2}{*}{ I. LINE } & \multicolumn{3}{|c|}{ DOWNTIME (MENIT) } & \multirow{2}{*}{ TOTAL } \\
\cline { 2 - 4 } & $\begin{array}{c}\text { NO } \\
\text { SPARES }\end{array}$ & $\begin{array}{c}\text { PM NOT } \\
\text { EFFECTIVE }\end{array}$ & $\begin{array}{c}\text { OPERATOR'S } \\
\text { ERROR }\end{array}$ & \\
\hline 1 & 10602 & 2400 & 2000 & 15002 \\
\hline 2 & 3963 & 200 & 1800 & 5963 \\
\hline 3 & 27804 & 1800 & 3200 & 32804 \\
\hline 4 & 5119 & 1200 & 2000 & 8319 \\
\hline 5 & 27917 & 900 & 3300 & 32117 \\
\hline
\end{tabular}

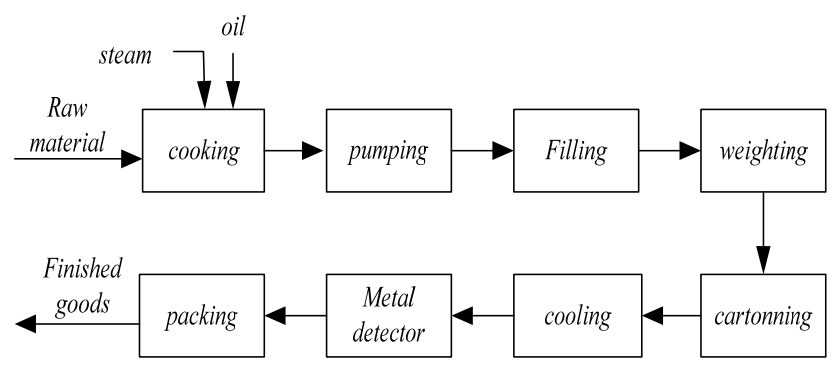

Gambar 2 Proses Produksi Line 3

Kerusakan yang terjadi pada mesin di perusahaan disebabkan karena penggunaan komponen dan part yang berulang kali untuk pergantian saat terjadi kerusakan sehingga frekuensi kerusakan semakin tinggi dan menambah downtime mesin. Berdasarkan Tabel II, Mesin Corazza A452 dan Corazza FF100 memiliki frekuensi kerusakan yang tinggi. Apabila terjadi kerusakan mesin, ketidaktersediaan suku cadang menyebabkan proses berhenti dan target produksi sulit untuk dicapai sehingga untuk mengurangi downtime perlu dilakukan kebijakan pengadaan suku cadang.

Dalam melakukan perawatan perlu disediakan suku cadang baik untuk pelaksanaan kegiatan perawatan terjadwal ataupun perbaikan ketika mesin mengalami kerusakan. Jika suatu suku cadang yang dibutuhkan tidak tersedia ketika terjadi kerusakan, maka hal ini tentunya dapat menambah downtime mesin dan mempengaruhi proses produksi. Tetapi jika perusahaan memiliki suku cadang yang berlebih maka dapat meningkatkan biaya inventori perusahaan.

Oleh sebab itu perlu dilakukan pengendalian pengadaaan suku cadang dengan menentukan terlebih dahulu komponen dan part kritis menggunakan metode Reliability Centered Spares. Setelah diketahui komponen dan part kritis maka dilakukan perhitungan kebutuhan suku cadang kritis menggunakan Poisson Process untuk mengetahui jumlah suku cadang yang dibutuhkan selama satu periode (1 tahun). Jumlah minimum dan maksimum stok juga perlu dilakukan sehingga kebutuhan suku cadang tetap tersedia pada saat dibutuhkan.

TABEL II

FREKUENSI KERUSAKAN MESIN

\begin{tabular}{|c|c|}
\hline Mesin & Frekuensi Kerusakan \\
\hline Corazza A452 & 261 \\
\hline Corazza FF100 & 147 \\
\hline Stephan kettle & 11 \\
\hline
\end{tabular}

Metode Reliability Centered Spares (RCS) merupakan suatu pendekatan untuk menentukan level inventori suku cadang. RCS terdiri dari beberapa pertanyaan dasar untuk memeriksa kebutuhan suku cadang, konsekuensi ketidaktersediaan dan antisipasi yang dilakukan ketika suku cadang tidak tersedia [2]. Pertanyaan tersebut antara lain:

1. What are the maintenance requirements of the equipment?

2. What happens if no spare part [3] is available?

3. Can the spares requirement be anticipated?

4. What stock holding of the spares is needed?

5. What if the maintenance requirement cannot be met? Jumlah kebutuhan suku cadang pada pertanyaan nomor 4 ditentukan menggunakan Poisson Process. Poisson Process merupakan teknik perhitungan jumlah kebutuhan suku cadang berdasarkan reliability [4]. Jumlah minimum dan maksimum stok dihitung berdasarkan nilai service level masing-masing criticality. Service level merupakan probabilitas ketersediaan suku cadang untuk memastikan jumlah suku cadang tetap tersedia pada saat dibutuhkan [5].

\section{METODE PENELITIAN}

A. Metode Pengumpulan Data

Data yang dibutuhkan untuk penelitian ini didapatkan melalui:

1. Studi Pustaka dan Literatur, dilakukan untuk mengkaji teori dan konsep dasar keilmuan yang akan digunakan dalam penelitian ini seperti Sparepart Management, Reliability Centered Spares, Poisson Process dan Service Level.

2. Studi Lapangan, dilakukan untuk memperoleh data dan informasi penunjang yang dibutuhkan dalam penyelesaian penelitian ini dengan melakukan observasi langsung dan wawancara.

Data yang dibutuhkan dalam penelitian ini meliputi:

1. Data downtime

2. Data failure history

3. Data mesin dan komponen penyusunnya

4. Data lead time pembelian suku cadang. 
B. Metode Pengolahan Data

Data mesin dan komponen penyusunnya digunakan untuk mengidentifikasi sistem, subsistem, equipment, subunit, component dan part. Setelah diketahui levelnya, dilakukan identifikasi suku cadang dan didapat bahwa suku cadang berada pada level component dan part. Komponen dan part kritis selanjutnya akan menjadi fokus penelitian. Reliability Centered Spares (RCS) digunakan untuk mengidentifikasi dan menganalisis komponen dan part kritis. Setelah itu dilakukan perhitungan kebutuhan komponen dan part menggunakan Poisson Process. Hasil yang didapat selanjutnya digunakan untuk menentukan minimum dan maksimum stok komponen dan part berdasarkan service level.

\section{Hasil Dan Pembahasan}

Mesin Corazza A452 dan Corazza FF100 memiliki banyak komponen dan parts yang dijabarkan strukturnya mulai dari sistem, equipment, subunit, komponen hingga part. Perusahaan mengadakan suku cadang pada level komponen dan part.

\section{A. Reliabiliity Centered Spares (RCS)}

Level paling kecil pada mesin Corazza A452 dan Corazza FF100 adalah part [6] . Berdasarkan replacement strategy [7], perusahaan menyediakan suku cadang pada level replacement part, replacement component dan replacement complete unit. Komponen dan part dianalisis kekritisannya dengan menggunakan Reliability Centered Spares (RCS) dengan empat faktor yaitu Consequence, Anticipation, Effect of Stockout dan Cost. Masing-masing faktor memiliki bobot yaitu $35 \%, 30 \%, 25 \%$ dan $10 \%$ yang didapat dari expert opinion. Keempat faktor tersebut memiliki lima level dan setiap komponen dan part akan ditetapkan berada pada level berapa. Selanjutnya level tersebut akan dikalikan dengan bobot masing-masing faktor dan dijumlahkan dan jumlah tersebut akan dikelompokkan ke dalam grup criticality seperti pada Tabel III. Perhitungan pada penelitian ini dilakukan pada grup A $(4,0-5,0)$ dan $\mathrm{B}(3,0-3,9)$. RCS worksheet dapat dilihat pada Tabel IV. RCS worksheet yang ditampilkan hanya sebagian dengan contoh part kritis pada Corazza A452. Penentuan level pada RCS worksheet dianalisis berdasarkan masing-masing faktor dan kegiatan yang dilakukan perusahaan pada komponen dan part tersebut.

Pada komponen cylinder, perhitungannya dilakukan dengan mengalikan level dan bobot faktor dengan hasil 3,45 sehingga cylinder termasuk criticality grup B. Hasil Criticality Analysis dengan RCS didapatkan 5 komponen dan 8 parts kritis pada mesin Corazza A452 dan pada mesin Corazza FF100 1 komponen dan 18 parts kritis yang termasuk dalam Criticality grup A dan B.
TABEL III

CRITICALITY INDEX

\begin{tabular}{|c|c|}
\hline Criticality & Criticality index \\
\hline High Critical & A $(4,0-5,0)$ \\
\hline Medium Critical & B $(3,0-3,9)$ \\
\hline Low Critical & C $(2,0-2,9)$ \\
\hline Not Critical & D $(1,0-1,9)$ \\
\hline
\end{tabular}

\section{B. Spares Classification}

Sebelum melakukan perhitungan kebutuhan komponen dan part dilakukan terlebih dahulu pengklasifikasian apakah komponen dan part tersebut termasuk repairable atau non repairable karena rumus perhitungan untuk repairable dan non repairable berbeda. Pada repairable terdapat variabel scrap rate sedangkan pada non repairable tidak ada variabel tersebut. Hasil pengklasifikasian dapat dilihat pada Tabel IV. Pada Tabel IV yang ditampilkan hanya suku cadang komponen pada mesin Corazza A452 dan Corazza FF100 dimana terdapat 1 komponen repairable dan sisanya termasuk non repairable.

TABEL IV

SPARE COMPONENT CLASSIFICATION

\begin{tabular}{|c|c|c|c|}
\hline \multirow{2}{*}{ Equipment } & Subunit & Component & $\begin{array}{c}\text { Spares } \\
\text { Classification }\end{array}$ \\
\hline \multirow{6}{*}{ Corazza A452 } & NCFR unit & Cylinder & Repairable \\
\cline { 2 - 4 } & FCFR Conveyor & Foil sensor & $\begin{array}{c}\text { Non } \\
\text { repairable }\end{array}$ \\
\cline { 2 - 4 } & Coding unit & Sensor encoder & $\begin{array}{c}\text { Non } \\
\text { repairable } \\
\text { repairable }\end{array}$ \\
\cline { 2 - 4 } & Glueing unit & $\begin{array}{c}\text { Sonsor } \\
\text { module }\end{array}$ \\
\cline { 2 - 4 } Corazza FF100 & Press heater & Catridge heater & $\begin{array}{c}\text { Non } \\
\text { repairable }\end{array}$ \\
\hline
\end{tabular}

C. Perhitungan Kebutuhan Spares

Pada Perhitungan kebutuhan Non Repairable terdapat beberapa variabel yaitu nilai confidence level $\mathrm{P}=95 \%, \mathrm{n}$ : jumlah spares, $\lambda t$ : laju kerusakan.

$$
P \leq \sum_{x=0}^{n} \frac{(\lambda t)^{x} e^{-\lambda t}}{x !}=e^{-\lambda t}\left[1+\lambda t+\cdots+\frac{(\lambda t)^{n}}{n !}\right] \text { (1) }
$$

Laju kerusakan dapat dihitung menggunakan rumus (2). Terdapat variabel MTBF : rata-rata waktu antar kerusakan pada periode waktu tertentu, $\mathrm{A}$ : jumlah kompnen dalam mesin, $\mathrm{M}$ : jam operasional mesin, dan $\mathrm{T}$ : periode.

$$
\lambda t=\frac{1}{M T B F} t=\frac{A \times N \times M \times T}{M T B F}
$$


TABEL V

RCS WORKSHEET CORAZZA A452

\begin{tabular}{|c|c|c|c|c|c|c|c|c|c|c|c|}
\hline \multicolumn{12}{|c|}{ RCS WORKSHEET PARTS CORAZZA A452 } \\
\hline \multirow{2}{*}{ Sub Unit } & \multirow{2}{*}{ Component } & \multirow{2}{*}{ Parts } & \multicolumn{2}{|c|}{ Consequence } & \multicolumn{2}{|c|}{ Anticipation } & \multicolumn{2}{|l|}{ Effect } & \multicolumn{2}{|l|}{ Cost } & \multirow{2}{*}{ Total } \\
\hline & & & Keterangan & Level & Keterangan & Level & Keterangan & Level & Keterangan & Level & \\
\hline NCFR unit & Cylinder & magnet field & hidden, operational & 4 & $\begin{array}{c}\text { Critical without } \\
\text { spares available } \\
\text { (frekuensi kerusakan } \\
>3 \text { kali dalam } 2 \\
\text { tahun) }\end{array}$ & 5 & $\begin{array}{c}\text { mesin mati dengan } \\
\text { kerusakan dapat } \\
\text { diperbaiki 1-2 jam }\end{array}$ & 3 & $\begin{array}{c}\text { Harga komponen Rp } \\
2.001 .000,00-\mathrm{Rp} \\
5.000 .000,00\end{array}$ & 4 & 4,05 \\
\hline \multirow{2}{*}{$\begin{array}{c}\text { NCFR } \\
\text { Conveyor }\end{array}$} & \multirow[t]{2}{*}{ Motor conveyor } & $\begin{array}{c}\text { kampas } \\
\text { brake }\end{array}$ & hidden, operational & 4 & $\begin{array}{l}\text { Not Critical without } \\
\text { spares available } \\
\text { (frekuensi kerusakan } \\
\text { 1-3 kali dalam } 2 \\
\text { tahun) }\end{array}$ & 3 & $\begin{array}{c}\text { mesin mati dengan } \\
\text { kerusakan dapat } \\
\text { diperbaiki }<1 \text { jam }\end{array}$ & 2 & $\begin{array}{c}\text { Harga komponen Rp } \\
501.000,00-\mathrm{Rp} \\
2.000 .000,00\end{array}$ & 3 & 3,1 \\
\hline & & bearing & hidden, operational & 4 & $\begin{array}{c}\text { Critical with spares } \\
\text { available (frekuensi } \\
\text { kerusakan }>3 \text { kali } \\
\text { dalam } 2 \text { tahun) }\end{array}$ & 4 & $\begin{array}{c}\text { mesin mati dengan } \\
\text { kerusakan dapat } \\
\text { diperbaiki }<1 \text { jam }\end{array}$ & 2 & $\begin{array}{c}\text { Harga komponen } \leq \\
\text { Rp 100.000,00 }\end{array}$ & 1 & 3,2 \\
\hline Forming unit & Turret & brake & hidden, operational & 4 & $\begin{array}{c}\text { Not Critical without } \\
\text { spares available } \\
\text { (frekuensi kerusakan } \\
\text { 1-3 kali dalam } 2 \\
\text { tahun) }\end{array}$ & 3 & $\begin{array}{c}\text { mesin mati dengan } \\
\text { kerusakan dapat } \\
\text { diperbaiki }<1 \text { jam }\end{array}$ & 2 & $\begin{array}{c}\text { Harga komponen Rp } \\
501.000,00-\mathrm{Rp} \\
2.000 .000,00\end{array}$ & 3 & 3,1 \\
\hline \multirow{3}{*}{$\begin{array}{c}\text { Blank } \\
\text { magazine unit }\end{array}$} & \multirow[b]{2}{*}{$\begin{array}{l}\text { Conveyor } \\
\text { magazine }\end{array}$} & toothed belt & hidden, operational & 4 & $\begin{array}{c}\text { Critical with spares } \\
\text { available (frekuensi } \\
\text { kerusakan }>3 \text { kali } \\
\text { dalam } 2 \text { tahun) }\end{array}$ & 4 & $\begin{array}{c}\text { mesin mati dengan } \\
\text { kerusakan dapat } \\
\text { diperbaiki 1-2 jam }\end{array}$ & 3 & $\begin{array}{c}\text { Harga komponen } \geq \\
\text { Rp 5.000.000,00 }\end{array}$ & 5 & 3,85 \\
\hline & & gear belt & hidden, operational & 4 & $\begin{array}{c}\text { Critical without } \\
\text { spares available } \\
\text { (frekuensi kerusakan } \\
>3 \text { kali dalam } 2 \\
\text { tahun) } \\
\end{array}$ & 5 & $\begin{array}{c}\text { mesin mati dengan } \\
\text { kerusakan dapat } \\
\text { diperbaiki }<1 \text { jam }\end{array}$ & 2 & $\begin{array}{c}\text { Harga komponen } \mathrm{Rp} \\
2.001 .000,00-\mathrm{Rp} \\
5.000 .000,00\end{array}$ & 4 & 3,8 \\
\hline & Glue unit & nozzle (4) & hidden, operational & 4 & $\begin{array}{c}\text { Critical without } \\
\text { spares available } \\
\text { (frekuensi kerusakan } \\
>3 \text { kali dalam } 2 \\
\text { tahun) } \\
\end{array}$ & 5 & $\begin{array}{c}\text { Mesin mati } \\
\text { dengan kerusakan } \\
\text { dapat diperbaiki } \\
\text { lebih dari } 3 \text { jam }\end{array}$ & 5 & $\begin{array}{c}\text { Harga komponen Rp } \\
501.000,00-\mathrm{Rp} \\
2.000 .000,00\end{array}$ & 3 & 4,45 \\
\hline Exit conveyor & Motor Conveyor & $\begin{array}{l}\text { kampas } \\
\text { brake }\end{array}$ & hidden, operational & 4 & $\begin{array}{l}\text { Not Critical without } \\
\text { spares available } \\
\text { (frekuensi kerusakan } \\
1-3 \text { kali dalam } 2 \\
\text { tahun) }\end{array}$ & 3 & $\begin{array}{c}\text { mesin mati dengan } \\
\text { kerusakan dapat } \\
\text { diperbaiki }<1 \text { jam }\end{array}$ & 2 & $\begin{array}{c}\text { Harga komponen Rp } \\
501.000,00-\mathrm{Rp} \\
2.000 .000,00\end{array}$ & 3 & 3,1 \\
\hline
\end{tabular}


Pada part toothed belt nilai MTTF/MTBF $=5358,31, \mathrm{~A}=$ 2 buah, $\mathrm{P}=95 \%, \mathrm{~N}=1$ mesin, $\mathrm{M}=720 \mathrm{jam} / \mathrm{bulan}$ dan $\mathrm{T}=1$ tahun (12 bulan). Berdasarkan iterasi perhitungan kebutuhan spares, nilai $\mathrm{P}=97,212 \%$ lebih besar dari $95 \%$ pada jumlah spares 9 buah sehingga kebutuhan suku cadang untuk part toothed belt adalah 9 buah.

Perhitungan kebutuhan Spares Repairable memiliki variabel sama seperti perhitungan kebutuhan spares non repairable.

$$
P \leq \sum_{x=0}^{n} \frac{(\lambda t)^{x} e^{-\lambda t}}{x !}=e^{-\lambda t}\left[1+\lambda t+\cdots+\frac{(\lambda t)^{n-1}}{(n-1) !}\right](3)
$$

Pada perhitungan laju kerusakan untuk kebutuhan spares repairable terdapat variabel RT : rata-rata waktu antar perbaikan dalam periode waktu tertentu.

$$
\lambda t=\frac{1}{M T B F} t=\frac{A \times N \times M \times R T}{M T B F}
$$

Pada komponen cylinder nilai MTTF/MTBF $=6647,25$, MTTR $=0,4999, \mathrm{~A}=1$ buah, $\mathrm{P}=95 \%, \mathrm{~N}=1$ mesin, $\mathrm{M}=720$ $\mathrm{jam} /$ bulan dan $\mathrm{T}=1$ tahun (12 bulan).

Terdapat tiga pendekatan untuk melakukan perhitungan kebutuhan spares repairable yaitu :

1. Pendekatan pertama

Pada pendekatan pertama, dilakukan perhitungan non repairable dan repairable. Jumlah kebutuhan spares dengan perhitungan non repairable adalah 3 buah dan nilai scrap rate $30 \%$ artinya terdapat 1 buah yang menjadi scrap. Jumah kebutuhan spares dengan perhitungan repariable adalah 2 buah. Total jumlah suku cadang yang mendukung kegiatan operasional menjadi 2 spares ditambah 1 spares yaitu 3 buah spares.

2. Pendekatan kedua

Pada pendekatan kedua, perhitungan $\lambda t$ menggunakan rumus (5). Nilai $\lambda_{t 2}$ menggunakan rumus (4) dan nilai $\lambda_{t 1}$ menggunakan rumus (2).

$$
\lambda t=\lambda_{t 2}+\lambda_{t 1} x \text { scrap rate }
$$

3. Pendekatan ketiga

Pada pendekatan ketiga, perhitungan spares menggunakan rumus Poisson. Pada tabel VI $\mathrm{P}_{1}$ : probabilitas komponen atau part rusak. $\mathrm{P}_{2}$ : probabilitas komponen atau part diperbaiki.

$P(n)=P\left(m=0 ; \lambda_{1}\right) \times P\left((m-n)=0 ; \lambda_{2}\right)+$ $P\left((m-n)=1 ; \lambda_{2}\right)+P\left((m-n) 2 ; \lambda_{2}+P(m=\right.$ $\left.1 ; \lambda_{1}\right) x\left(p\left((m-n)=0 ; \lambda_{2}+P((m-n)=\right.\right.$ $\left.\left.1 ; \lambda_{2}\right)\right)+P\left(m=2 ; \lambda_{1}\right) x P\left((m-n)=0 ; \lambda_{2}\right.$

Jumlah kebutuhan spares berdasarkan perhitungan iterasi menggunakan rumus (6) didapat ketika nilai $\mathrm{P}$ lebih besar dari 95\%. Confidence level merupakan tingkat kepercayaan.

TABEL VI

PENDEKatan Ketiga REPAIRABLE ITEM

\begin{tabular}{|c|c|c|}
\hline Number of spares & To scrap $P_{1}$ & In repair $P_{2}$ \\
\hline $\mathrm{n}$ & $\mathrm{m} ;$ mean $=\lambda_{1}$ & (n-m); mean $=\lambda_{2}$ \\
\hline 0 & 0 & 0 \\
\hline 1 & 0 & $0 ; 1$ \\
\hline & 1 & 0 \\
\hline 2 & 0 & $0 ; 1 ; 2$ \\
\hline & 2 & 0 \\
\hline$\ldots$ & $\ldots$ & $\ldots$ \\
\hline $\mathrm{n}$ & 0 & $0 ; 1 ; 2 ; \ldots ; \mathrm{n}$ \\
\hline & 1 & $0 ; 1 ; 2 ; \ldots ;(\mathrm{n}-1)$ \\
\hline & 2 & $0 ; 1 ; 2 ; \ldots ;(\mathrm{n}-2)$ \\
\hline & $\ldots$ & $\ldots$ \\
\hline & $\mathrm{m}$ & $0 ; 1 ; 2 ; \ldots ;(\mathrm{n}-\mathrm{m})$ \\
\hline & $\ldots$ & $\ldots$ \\
\hline & $\mathrm{n}-1$ & $0 ; 1$ \\
\hline & $\mathrm{n}$ & 0 \\
\hline
\end{tabular}

Berdasarkan nilai confidence level 95\%, kebutuhan komponen cylinder dalam 1 tahun harus disediakan sebanyak 3 buah spares, dimana $n-1=2$ sehingga $n=3$ buah spares.

D. Penentuan Nilai Service Level dan Stock Level

Penentuan service level dilakukan untuk menghindari overstocking dan understocking. Penentuan service level berdasarkan criticality komponen dan parts yang dibagi menjadi 4 grup. Pada Tabel VII dapat dilihat komponen dan parts yang temasuk pada high criticality grup A memiliki service level $99 \%$ dan medium criticality grup B memiliki service level $95 \%$.

TABEL VII

SERVICE LEVEL BERDASARKAN CRITICALITY INDEX

\begin{tabular}{|c|c|c|}
\hline Criticality & Criticality Index & Service Level \\
\hline High Critical & A $(4,0-5,0)$ & $99 \%$ \\
\hline Medium Critical & B $(3,0-3,9)$ & $95 \%$ \\
\hline Low Critical & C $(2,0-2,9)$ & $90 \%$ \\
\hline Not Critical & D $(1,0-1,9)$ & $75 \%$ \\
\hline
\end{tabular}

Maksimum dan minimum stok dapat dihitung berdasarkan service level dengan variabel $\mathrm{M}$ adalah rata-rata kebutuhan selama periode dan $\mathrm{K}$ adalah faktor yang bergantung pada nilai service level. Nilai K untuk service level $99 \%$ adalah 2,3 dan nilai 1,7 untuk service level 95\%. Perhitungan rumus maksimum dan minimum stok dapat dilihat pada rumus (7) dan (8).

$$
\begin{aligned}
& \text { Maksimum stok }=M+K \sqrt{M} \\
& \text { Minimum stok }=K \sqrt{M}
\end{aligned}
$$


Pada part bearing unit NCFR Conveyor mesin Corazza A452 memiliki install quantity sebanyak 7 buah, annual demand 21 buah. Pemesanan dalam 1 tahun periode dilakukan dua kali sehingga kebutuhan rata-rata adalah 11 buah. Part ini termasuk grup B dalam criticality dan nilai service level part ini adalah 95\% dengan 1,7 sebagai nilai $\mathrm{K}$. Tabel VIII merupakan jumlah kebutuhan suku cadang dan stock level masing-masing part dan komponen kritis.

TABEL VIII

\begin{tabular}{|c|c|c|c|c|c|c|c|}
\hline \multirow[b]{2}{*}{ Equipment } & \multirow[b]{2}{*}{ Subunit } & \multirow[b]{2}{*}{ Component/part } & \multirow{2}{*}{$\begin{array}{c}\text { Service } \\
\text { level }\end{array}$} & \multirow[b]{2}{*}{ D } & \multirow[b]{2}{*}{$\mathbf{M}$} & \multicolumn{2}{|c|}{ Stock level } \\
\hline & & & & & & $\begin{array}{l}\text { Min } \\
\text { stock }\end{array}$ & $\begin{array}{l}\text { Max } \\
\text { stock }\end{array}$ \\
\hline \multirow{13}{*}{ Corazza A452 } & \multirow{2}{*}{ NCFR unit } & magnet field & 0,99 & 4 & 4 & 4 & 8 \\
\hline & & cylinder & 0,95 & 4 & 4 & 4 & 8 \\
\hline & \multirow{3}{*}{ NCFR conveyor } & kampas brake & 0,95 & 21 & 11 & 6 & 17 \\
\hline & & bearing & 0,95 & 21 & 11 & 6 & 17 \\
\hline & & foil sensor & 0,95 & 20 & 10 & 6 & 16 \\
\hline & \multirow{2}{*}{ Forming unit } & brake & 0,95 & 4 & 4 & 4 & 8 \\
\hline & & sensor proximity & 0,95 & 5 & 5 & 4 & 9 \\
\hline & \multirow{2}{*}{ Blank magazine unit } & toothed belt & 0,95 & 9 & 5 & 4 & 9 \\
\hline & & gear & 0,95 & 6 & 6 & 5 & 11 \\
\hline & Coding unit & sensor encoder & 0,95 & 5 & 5 & 4 & 9 \\
\hline & \multirow{2}{*}{ Glueing unit } & nozzle & 0,99 & 21 & 11 & 6 & 17 \\
\hline & & module & 0,95 & 14 & 7 & 5 & 12 \\
\hline & Exit Conveyor & kampas brake & 0,95 & 4 & 4 & 4 & 8 \\
\hline \multirow{19}{*}{$\begin{array}{c}\text { Corazza } \\
\text { FF100 }\end{array}$} & \multirow{5}{*}{ Body foil unit } & blade & 0,95 & 9 & 9 & 6 & 15 \\
\hline & & pulley & 0,95 & 6 & 6 & 5 & 11 \\
\hline & & timing belt & 0,95 & 4 & 4 & 4 & 8 \\
\hline & & ball bearing & 0,95 & 7 & 7 & 5 & 12 \\
\hline & & holding brake & 0,95 & 8 & 8 & 5 & 13 \\
\hline & \multirow{3}{*}{ cell turnplate unit } & sincro belt & 0,95 & 5 & 5 & 4 & 9 \\
\hline & & kampas brake & 0,95 & 4 & 4 & 4 & 8 \\
\hline & & bearing & 0,95 & 5 & 5 & 4 & 9 \\
\hline & \multirow{4}{*}{ filler unit } & kampas brake & 0,95 & 4 & 4 & 4 & 8 \\
\hline & & piston & 0,95 & 3 & 3 & 3 & 6 \\
\hline & & nozzle & 0,99 & 3 & 3 & 3 & 6 \\
\hline & & bearing & 0,95 & 5 & 5 & 4 & 9 \\
\hline & \multirow{5}{*}{ Top foil unit } & ball bearing & 0,95 & 5 & 5 & 4 & 9 \\
\hline & & holding brake & 0,95 & 5 & 5 & 4 & 9 \\
\hline & & blade & 0,95 & 9 & 9 & 6 & 15 \\
\hline & & timing belt & 0,95 & 4 & 4 & 4 & 8 \\
\hline & & brake & 0,95 & 7 & 7 & 5 & 12 \\
\hline & Folder unit & spring & 0,95 & 5 & 5 & 4 & 9 \\
\hline & Press heater & catridge heater & 0,95 & 4 & 4 & 4 & 8 \\
\hline
\end{tabular}

\section{KESIMPULAN}

Berdasarkan penelitian yang telah dilakukan, didapatkan kesimpulan yaitu jenis suku cadang yang disediakan perusahaan berdasarkan pada replacement stragety ada 3 yang diterapkan perusahaan yaitu replacement part, replacement complete unit dan replacement component. Berdasarkan Criticality Analysis dengan menggunakan metode Reliability Centered Spares (RCS), komponen dan part yang termasuk dalam grup A (High Critical) yaitu magnet field pada NCFR unit, nozzle pada Glueing unit mesin Corazza A452 dan nozzle pada Filler unit mesin Corazza FF100. Komponen dan parts yang termasuk dalam grup B (Medium Critical) ada 7 komponen dan 23 parts. Pada komponen dan part kritis dilakukan perhitungan jumlah kebutuhan suku cadangnya dengan metode Poisson Process seperti pada toothed belt non repairable sebanyak 9 buah dan cylinder repairable sebanyak 3 buah. Jumlah minimum dan maksimum stok didapat berdasarkan faktor service level $99 \%$ untuk high critical seperti magnet field pada NCFR unit, nozzle pada glueing unit dan nozzle pada filler unit, $95 \%$ untuk medium critical seperti cylinder pada NCFR unit. Berdasarkan penelitian ini dapat ditentukan pengelolaan suku cadang kritis pada Corazza A452 dan Corazza FF100 dengan metode Reliability Centered Spares. 


\section{DAFTAR PUSTAKA}

[1]. Ebeling, C., Reliability Engineering: An Introduction to Reliability and Maintainability Engineering, Singapore, McGraw-Hill Companies Inc, 1997.

[2]. Slater, P. (2013). The What, Why and How of Reliability Centered Spares (RCS) Process. Diambil kembali dari SparePartsKnowHow: SparePartsKnowHOw.com

[3]. Muhaxheri, Driton, Framework for Evaluation of Strategies for Pooling of Repairable Spare Parts. Thesis, Master of Production Management, Lund University, 2010.

[4]. Fukuda, J. (2008). Spare Parts Stock Level Calcualtion.

[5]. Gopalakrishnan, \& Banerji, A. (2013). Maintenance and Spare Parts Management. New delhi: PHI Learning Private Limited.

[6]. International Organization for Standardization 2006, second edition : Petroleum, pertrochemical and natural gas industries - Collection and exchange of reliability and maintenance data for equipment, ISO 14224:2006(E), International Organization for Standardization, Switzerland.

[7]. Kaki, A., Forecasting in End-Of-Life Spare Parts Procurement. Thesis, Master of Science in Technology, Helsinki University of Technology, 2007. 